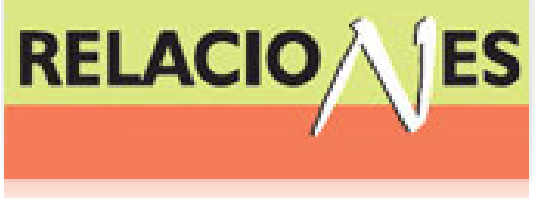

Relaciones. Estudios de historia y sociedad ISSN: 0185-3929

relacion@colmich.edu.mx

El Colegio de Michoacán, A.C

México

Granados Campos, Luis Roberto

Ecología cultural: metamorfosis de un concepto holometábolo

Relaciones. Estudios de historia y sociedad, vol. XXXI, núm. 123, 2010, pp. 183-217

El Colegio de Michoacán, A.C

Zamora, México

Disponible en: http://www.redalyc.org/articulo.oa?id=13715893007

- Cómo citar el artículo

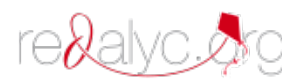

- Número completo

- Más información del artículo

Página de la revista en redalyc.org

Sistema de Información Científica

Red de Revistas Científicas de América Latina, el Caribe, España y Portugal Proyecto académico sin fines de lucro, desarrollado bajo la iniciativa de acceso abierto 


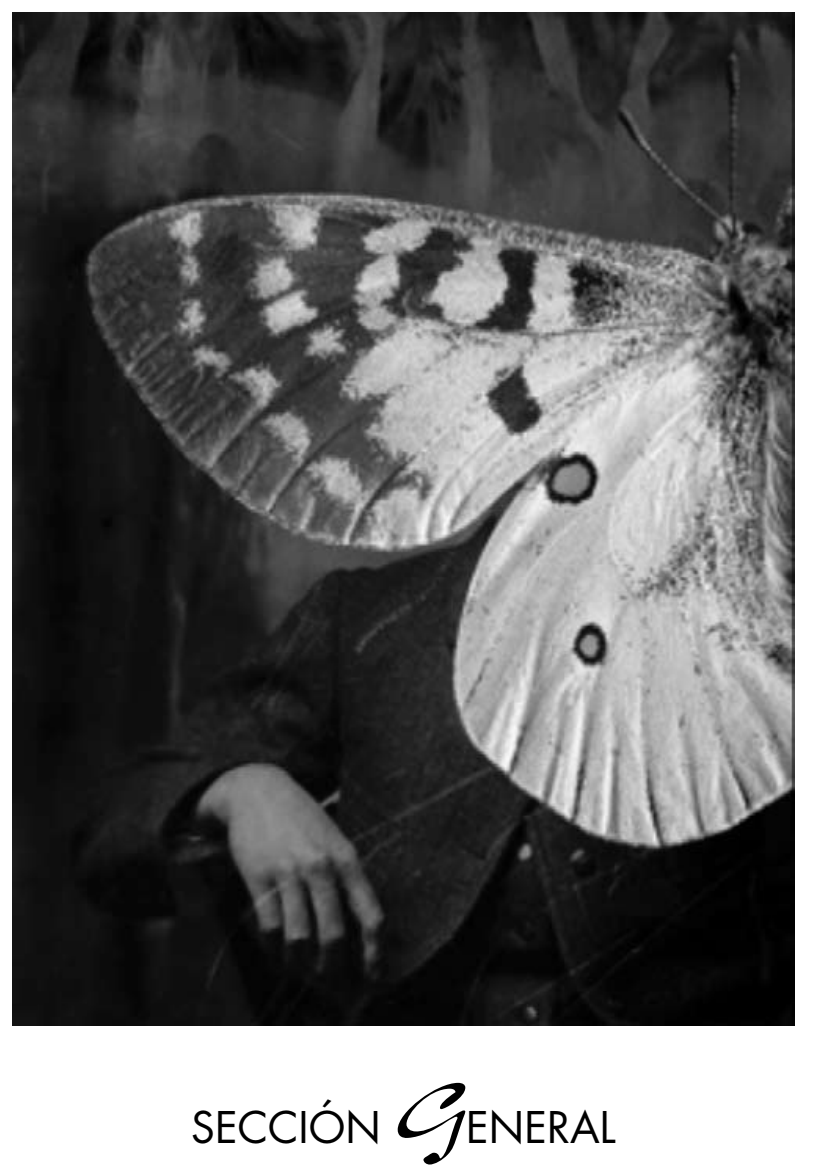




\title{
ECOLOGÍA CULTURAL: \\ METAMORFOSIS DE UN CONCEPTO HOLOMETÁBOLO
}

\author{
Luis Roberto Granados Campos* \\ Universidad Autónoma de Tlaxcala
}

Desde una óptica crítica de los postulados centrales de la ecología cultural, apunto que la forma en que extendemos nuestra mano hacia la naturaleza esta determinada por las relaciones sociales, elemento constitutivo y cohesionador de lo social humano: la sociedad y su cultura. De este modo he perfilado una categoría de análisis socioecológico que permite comprender la operación del conjunto sociedad-naturaleza.

(Ecología, socioecología, autoecología, relación social)

INTRODUCCIÓN

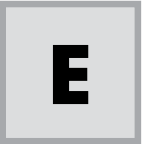

ste trabajo propone abordar el problema de las relaciones sociedad-naturaleza desde una perspectiva crítica del enfoque teórico-metodológico de la ecología cultural. Ha sido mi interés partir de este punto con el propósito de recomponer el concepto de ecología empleado de manera limitada por esta corriente antropológica. A partir de esta revisión presento un esbozo del posible desarrollo socioecológico de la disciplina ecocultural, delineando algunos de sus conceptos y enfoques clave.

La base del vínculo sociedad-naturaleza se constituye de relaciones sociales y en ellas este vínculo explica sus características. Las relaciones sociales a su vez determinan las condiciones materiales, las formas y las aspiraciones de vida del hombre. Son las estrategias humanas, naturalmente sociales, de reproducción de su existencia, las que caracterizan la dinámica social, política y cultural de las sociedades en general. El pun-

\footnotetext{
*1_u_i_s_roberto@yahoo.com.mx
} 
to de partida fundamental para comprender esa dinámica es la relación del hombre con el hombre y no la del hombre con su medio natural. Las relaciones sociales poseen núcleos o arterias vitales que las caracterizan; algunas de ellas son, por ejemplo, la solidaridad, el poder, la lógica del capital y el deseo de saber. Establecida y reconocida esta base, preciso que el enfoque descrito lo he ocupado en la exploración de uno de estos núcleos centrales de producción y reproducción social de la vida intangible y material del hombre: la relación de poder, investigación realizada en la región del volcán La Malinche, México, de la que forma parte la presente reflexión.

¿ECología CULTURAL O BIOANTROPOLOGía?

El poder de la naturaleza

La ecología cultural es concebida fundamentalmente como un esfuerzo disciplinario que intenta comprender la dinámica social humana desde la interacción entre cultura y medio natural, tomando como base el desarrollo de conocimiento, la tecnología y la organización del trabajo (Boehm Schoendube 2005, 80). Coincido en que esta perspectiva antropológica ha generado la posibilidad de abordar nuevos problemas de investigación y metodologías en el campo de la ciencia social (González Jácome y Del Amo Rodríguez 1999, 22).

La ecología cultural constituye una ramificación del evolucionismo materialista de Leslie White y V. Gordon Childe, entre otros, cuyas raíces se remontan a Lewis Henry Morgan y E. B. Taylor en el siglo XIX (Ortner 1993, 17). Y aunque el auge de esta escuela se inicia en la década de los sesenta del siglo XX, el concepto de "ecología cultural" fue acuñado por primera vez en 1955 por Julian H. Steward, refiriéndolo a un método de análisis social cuyo propósito era "determinar hasta qué punto los modelos de conducta implicados en la explotación del entorno [es decir, los rasgos conductuales más vinculados a las actividades de subsistencia] afectan a otros aspectos de la cultura" (Steward 1955, 42).

De acuerdo con Eric Wolf (1987, 27-34), el renacimiento antropológico del evolucionismo fue una de las respuestas metodológicas que la 
antropología dio al entrampamiento conceptual y operativo en que el funcionalismo había sumido a esta disciplina. La antropología funcionalista, constreñida en sus investigaciones de campo por limitaciones humanas de tiempo y recursos materiales, daba por hecho que las sociedades eran sistemas locales cerrados cuyos componentes y fenómenos estaban interna y mutuamente condicionados (homeóstasis), dando lugar, así, a estudios de "microcosmos" supuestamente aislados.

Pretendiendo romper este cerco conceptual y metodológico, el modelo de evolución general del pensamiento neoevolucionista introdujo en los estudios antropológicos un criterio de análisis hipotéticamente histórico, empero unidireccional y progresista, que luego adquiriría el estatus de "teoría": la ecología cultural (Wolf 1987, 27). De manera esquemática puedo describir ese criterio, en mi perspectiva no históricosocial sino ambiental-evolutivo, bajo el modelo explicativo de "desarro1lo" de las sociedades -un desarrollo lineal y supuestamente perfeccionado- de "bandas-tribus-jefaturas-estados", donde las condiciones del supuesto entorno no humano son determinantes en el proceso. Aquí, por supuesto, los primeros estadios (bandas) son considerados como formas defectuosas, deficientes, imperfectas o subdesarrolladas de los posteriores, es decir, los nuestros (estados). Insinuar el carácter teratológico de la sociedad moderna, verificable en muchas formas deplorables de vida cotidiana actual (considérese, por ejemplo, la abatida calidad de vida real de gran parte de la población humana, su miseria y las muertes masivas por hambre, enfermedades, violencia e injusticia) sería un insulto para el orgulloso pensamiento evolucionista contemporáneo.

No es difícil identificar en esa posición ambiental-evolutiva una actitud refleja y simétrica, opuesta pero idéntica a los dogmas teológicos de la intervención sobrenatural en el devenir humano. El evolucionismo como protesta racionalista a estos dogmas cometió el pecado de permutar una especie de fuerza mágica universal (la divina) por otra (la natural). Y de este error, como veremos, la ecología cultural no salió bien librada, a pesar de la advertencia que en ese sentido ya hacía uno de sus eminentes precursores, el arqueólogo australiano Vere Gordon Childe: "Al usar la expresión "evolución social", quienes estudian la ciencia del hombre-la antropología en el sentido más amplio-han tomado la "evo- 
lución" como una especie de fuerza mágica universal que realiza el trabajo de los factores individuales concretos, determinantes del curso de la historia" (Gordon Childe 1988, 7).

$\mathrm{Al}$ revisar el desarrollo de las sociedades humanas en ambientes diversos y apoyado fundamentalmente en el testimonio arqueológico, Gordon Childe ha dejado entrever que son los hechos concretos del hombre en sociedad los que determinan su devenir (desarrollo), el curso de su historia, y no la "fuerza mágica" de la naturaleza. Es el medio ecuménico o social y no el natural el que contiene, condiciona y afecta a las sociedades humanas. Señala este autor que, desde luego " [...] la cultura representa los medios por los cuales las sociedades se adaptan a sus ambientes, para sobrevivir y multiplicarse; y ocupan el lugar de los cambios corporales y los instintos que sirven a los animales para el mismo propósito. A su vez, esta peculiaridad es una función de la forma en que la cultura evoluciona y se transmite" (ibid., 167).

Sin embargo, en su desarrollo empírico y conceptual, la ecología cultural se limitó al estudio de las formas particulares en que el medio natural y sus productos valorados como recursos afectaban el desarrollo de las sociedades. De este modo podrían explicarse después sobre esa base las formas específicas en que los grupos humanos se organizan y funcionan, sosteniendo una relación concreta con su ambiente socio-natural (Tomé 2005, 43-48). Veo así que para la ecología cultural, además de no haberse librado del enfoque funcional-localista, es aplicable el problema de la confusión entre lo metodológico y lo teórico, enunciado por Eric Wolf en los siguientes términos:

Ciertamente la antropología cultural empezó como antropología mundial [...] [después] los antropólogos pasaban de un interés primario en formas culturales al estudio de "culturas vivientes", de formas de vida de poblaciones particulares en hábitats delimitados localmente. El trabajo de campo, es decir, la comunicación directa con la gente y la observación consiguiente de las actividades diarias in situ, llegaron a ser característica principal del método antropológico [...] Sin embargo, el éxito mismo del método engañó a quienes lo usaban y les dio una falsa confianza. Se les hizo fácil convertir consideraciones de método meramente heurísticas en postulados teóricos sobre la sociedad y la cultura $(1987,27-28)$. 
A pesar de las críticas que, por ejemplo, los antropólogos simbólicos hacían a los ecólogos culturales, considerando que estos estaban "enredados en un cientificismo negligente y estéril, contando calorías y midiendo gotas" (Ortner, 1993: 20), autores como Eric Wolf $(1967,1987)$, John Murra (1972), Roy A. Rappaport (1987), Richard N. Adams (1978), Ángel Palerm (1998), Marvin Harris $(1978,1993)$, Brigitte Boehm Schoendube (1991, 2001, 2005, 2006), Jaime L. Espín Díaz $(1983,1987)$ y Andrés Fábregas Puig (2009), entre otros, se han esforzado por analizar bajo ese vibratum intelectual, de manera implícita o explícita y en distintos grados y matices, fenómenos culturales de naturaleza eminentemente histórico-social tales como la formación de regímenes de gobierno, guerras, ritos y religiones, tecnología, arte e instituciones en sociedades "primitivas" o "complejas".

Cerdos, hombres y Dios

Para Roy A. Rappaport, el enfoque de la ecología cultural, al centrar su interés en el análisis de las interacciones físicas o energéticas existentes entre poblaciones humanas y comunidades bióticas, goza de evidentes ventajas:

Las poblaciones humanas consideradas como unidades son conmensurables a las demás unidades con las que interactúan para dar lugar a redes alimentarias, comunidades bióticas y ecosistemas, La apropiación de energía a costa de las otras unidades y los intercambios de material con ellas pueden ser medidos y por tanto descritos en términos cuantitativos (Rappaport 1987, 5-6).

Propone así, por ejemplo, estimar la capacidad de carga (sustentación) del territorio mediante la siguiente fórmula (misma fórmula que emplea para estimar la capacidad de carga de hombres y de animales [cerdos]): $P=(T / R+Y) Y / A$, donde $P=$ población que puede ser sustentada, $T=$ total de tierra cultivable, $R=$ duración del periodo de barbecho en años, $Y=$ duración del periodo de cultivos en años, $A=$ superficie de la tierra cultivada necesaria para proporcionar a un "individuo medio" 
la cantidad de alimentos que ordinariamente obtiene de las plantas cultivadas por año (Rappaport 1987, 101). De este modo para el autor no existe inconveniente en considerar a las poblaciones humanas como poblaciones espaciales reguladas por el ambiente, ni en estudiarlas como poblaciones en el sentido de la ecología animal. La comunidad humana es en Rappaport, un agregado de organismos que establecen relaciones tróficas con el medio natural en el que subsisten (ibid., 243).

Ciertamente Rappaport reconoce que estas poblaciones humanas, además de sostener relaciones orgánicas con los elementos bióticos y abióticos de su entorno, también establecen relaciones de intercambio material y genético con otras poblaciones humanas. Afirma que estas relaciones supralocales no pueden ser ignoradas en el análisis "ecológico", es decir, en un análisis de carácter ambiental donde tales influencias, contingentes para el autor, son valoradas en su carácter meramente biológico y tecnológico, pero no como elementos sustanciales desde el punto de vista sociocultural o político para explicar la estructura y dinámica social del grupo local.

Rappaport, adherido aún al funcionalismo antropológico, adolece también del mismo localismo que limitó la perspectiva teórica y metodológica de este enfoque al explicar los fenómenos sociales como respuestas per se a las condiciones y dinámica del entorno natural. Para él, la cultura es considerada esencialmente como una de las estrategias por medio de las cuales los "animales de la especie humana" logran adaptarse a su medio. En su estudio sobre la función del ritual entre los tsembaga de la comunidad maring, en las montañas de Nueva Guinea, llega a considerar que los grupos humanos vecinos de este pueblo son menos significativos para su sobrevivencia que el medio ambiente de donde obtienen sus alimentos $(1987,244)$.

La cuestión del ejercicio del poder en el seno y entre los grupos sociales es abordada de manera periférica por Rappaport (1987). Sin explorar demasiado este problema, Rappaport considera que el poder político es un producto, en sentido matemático, de los hombres, los recursos y la organización $(1987,256)$. Señala que los maring carecen de autoridades que tengan a su disposición hombres y recursos susceptibles de ser organizados para imponerse por la fuerza al medio físico y social. Explica que dada esta carencia, son las convenciones del ciclo ritual las que re- 
gulan el comportamiento al interior y al exterior del grupo social. Por ejemplo, al interior, el ritual del sacrificio de cerdos reestablece la convivencia y la identidad comunitarias, y al exterior, la observancia de treguas con otros grupos humanos. Aquí el ritual ejerce el poder.

En consecuencia, Rappaport sugiere que entre los pueblos del mundo se podría discernir un continuum que va de las sociedades gobernadas por convenciones sacralizadas a las sociedades en las que las autoridades están dotadas de escasa sacralización, pero de un gran poder. Además vincula este proceso con el desarrollo tecnológico señalando que " [...] es probable que la complejidad tecnológica coloque armas muy eficaces en las manos de las autoridades, armas que no suelen ser asequibles a sus súbditos. Una autoridad dotada de gran poder puede prescindir de la sacralización: como decía Napoleón, "Dios está del lado de la artillería pesada" (Rappaport 1987, 256) (Véase cuadro 1).

En la línea de pensamiento de Rappaport, el ejercicio del poder y la capacidad de desarrollo tecnológico de las sociedades humanas se encuentran regulados por las condiciones del entorno natural. Las convenciones del rito o la cantidad de balas necesarias para subsistir dependen de las posibilidades que presenta el medio biofísico. En suma, rito y conflicto dependen o están en función no del entorno ecuménico sino de los recursos materiales circundantes. Las decisiones humanas son finalmente, en Rappaport, estrategias de adaptación.

Cuadro 1. Sociedad, poder y desarrollo tecnológico en Rappaport, 1987.

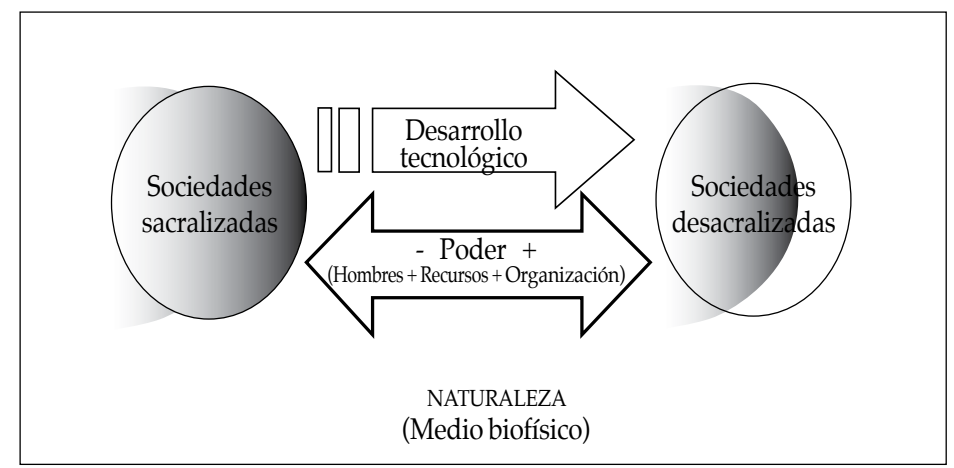

Fuente: Elaboración propia. 
Un asomo de biología política

Por su parte, Richard N. Adams, al abordar directamente el estudio del poder junto con otras categorías sociales, físicas y ecológicas tales como las estructuras disipativas de la energía antropofílica y los procesos mentales implícitos en lo que él llama "la evolución de la sociedad humana", señala que el hombre, en su búsqueda de garantizar su sobrevivencia, ejerce influencia sobre otros como recurso simple de una estrategia más general que tiene como propósito enfrentar y controlar su medio natural (Adams 1978, 19). De este modo los seres humanos, inmersos en un gran sistema natural regido por fenómenos y leyes suprahumanas, se encuentran impelidos a controlar su medio natural y ecuménico.

Según Adams, se puede hablar de "poder" solo en el sentido de "controlar hombres" $(1978,25)$. Para él existe una diferencia entre control y poder. El control es el proceso físico de manipular los elementos del medio ambiente mediante el intercambio de energía, y el poder es un aspecto que implica relaciones entre los sujetos. Pero al parecer esta relación es indirecta porque la base de la estructura de poder está en la capacidad (y necesidad) de control del medio. Ejercer el poder es un proceso mediante el cual "[...] un actor, alterando o amenazando con alterar el ambiente de un segundo actor, logra influirlo para que adopte una conducta determinada. El segundo actor decide, de manera racional e independiente, conformarse a los intereses del primer actor ya que es conveniente para sus propios intereses" (Adams 1978, 90).

Pero además, Adams sostiene que lo que los sociólogos y antropólogos denominan, "muy a la ligera", relaciones sociales, son en primera instancia, asuntos de la mente, es decir, que el poder reside en forma de ideas en la mente de las personas. Ideas que son puestas a prueba en el terreno de los hechos. Así, el poder es un complejo que implica conjunciones particulares de lo energético (relaciones prácticas con el medio ambiente) y lo "mentalístico", por lo tanto "una relación social se refiere a un conjunto particular de procesos psicológicos, procesos evidentes de conducta, y artefactos, que involucran a dos o más individuos" (ibid., 62).

El autor establece de este modo que las relaciones de poder se reconocen fundamentalmente en términos de dos distinciones elementales: 
a) si la relación entre dos actores es o no de equivalencia y b) si no, cuál de ellos se encuentra en posición subordinada y cuál en posición subordinante (Adams 1978, 64). De hecho, toda relación social puede implicar el ejercicio de poder puesto que cada sujeto posee alguno, que utiliza en determinadas situaciones.

Finalmente, para Adams el ser humano ha vivido siempre en un equilibrio constante y dinámico de relaciones de poder. Pero el poder es para este autor, como hemos dicho, solo una parte del esfuerzo general que hacen los hombres por dominar el entorno extrahumano. De hecho, y al final de cuentas, descubrimos que el concepto de poder es revestido aquí más como una categoría naturalista que sociológica:

En el fondo, el problema de la supervivencia humana es un proceso físico y químico, así como ecológico y biológico. Esto sugiere que para alcanzar una mejor comprensión del poder y del sistema dentro del cual funciona debemos comprender las áreas antes mencionadas. No acudimos a una especie de reduccionismo. Más bien, reconocemos que el proceso social de poder opera como parte de un sistema físico y energético, y que por ende hay aspectos de su funcionamiento que no pueden entenderse desvinculados del papel que juegan en ese sistema (Adams 1978, 34).

Y un ejemplo de esto que afirma Richard Adams es la respuesta que plantea Marvin Harris (1993) al problema del surgimiento del poder institucionalizado, es decir, del Estado. Como veremos a continuación, Harris asume, también dentro de un determinismo ambiental ecocultural, que fueron condiciones del entorno biofísico las que propiciaron en principio el surgimiento y consolidación de formas de poder social coercitivo a partir de primitivas jefaturas redistributivas.

Desarrollo tecnológico + abusones + resignación $=$ Estado

Criticando a Thomas Hobbes, quien creía que el ímpetu por el poder ("un perpetuo y desazonador deseo de poder por el poder") era inherente al género humano, Marvin Harris considera que la mayor parte de la historia del hombre se ha caracterizado precisamente por la ausencia de esa inclinación. Alegremente señala que "con todo, la vida del 
hombre transcurrió durante treinta mil años sin necesidad de reyes ni reinas, primeros ministros, presidentes, parlamentos, congresos, gabinetes, gobernadores [...], coches patrulla, cárceles ni penitenciarías" (Harris 1993, 6).

Explica que la progresiva estratificación social guardaba una relación proporcional directa con la creciente capacidad de almacenaje de los excedentes de alimentos. Cuanto más abundante y menos perecedera era la cosecha, tanto más crecían las posibilidades de los hombres responsables de la redistribución de estos excedentes de adquirir poder sobre el pueblo:

En tiempos de escasez la gente acudía a ellos en busca de comida y ellos, a cambio pedían a los individuos con aptitudes especiales que fabricaran ropa, vasijas, canoas o viviendas de calidad destinadas a su uso personal. Al final, el redistribuidor ya no necesitaba trabajar en los campos para alcanzar y superar el rango de gran hombre. La gestión de los excedentes de cosecha, que en parte seguía recibiendo para su consumo en festines comunales y otras empresas de la comunidad, tales como expediciones comerciales y bélicas, bastaba para legitimar su rango. De forma creciente, este rango era considerado por la gente como un cargo, un deber sagrado transmitido de una generación a otra con arreglo a normas de sucesión hereditaria. El gran hombre se había convertido en jefe, y sus dominios ya no se limitaban a una sola aldea autónoma de pequeño tamaño sino que formaban una gran comunidad política, la jefatura (Harris 1993, 37).

Afirma, entonces, que fue la carencia de tierras con potencial productivo a donde los pueblos pudieran reubicarse para evitar los abusos de jefes que intentaban imponerles medidas coercitivas y de control tales como cuotas agrícolas, esquemas de redistribución desigual, trabajo forzado e impuestos, junto con la alta producción y capacidad de almacenaje de alimentos de tipo menos perecedero que los tubérculos, tales como el arroz, el maíz, el trigo y otros cereales de larga conservación, lo que permitió la estabilidad y el desarrollo de las jefaturas así como el incremento y ejercicio de su capacidad impositiva.

De esta manera Harris explica, por ejemplo, el surgimiento del Estado sumerio en el Medio Oriente, al sur de Irán e Irak, entre los años 3500 
y $3200 \mathrm{aC}$, donde los pobladores pronto llegaron a depender totalmente del regadío para sus labores agrícolas:

[...] quedando así inadvertidamente atrapados en la condición final para la transición hacia el Estado. Cuando los aspirantes a reyes comenzaron a ejercer presiones para exigirles más impuestos y mano de obra para la realización de obras públicas, los plebeyos de Sumer vieron que habían perdido la opción de marcharse a otro lugar. ¿Cómo iban a llevarse consigo acequias, sus campos irrigados, jardines y huertas, en las que habían invertido el trabajo de generaciones? (Harris 1993, 58-59).

La idea subyacente al análisis de Harris refleja el enfoque de la ecología cultural sobre la existencia de sociedades supuestamente inconexas y autorreguladas por un ambiente natural específico. Esta perspectiva ha impedido a diversos autores valorar y reconocer procesos que atraviesan y van más allá del hipotético caso social aislado y condicionado localmente, procesos de carácter histórico, político y cultural que se mueven desde, entre y a través de ellos, vinculándolos, enriqueciéndolos, condicionándolos o erosionándolos y transformándolos.

\section{El termostato de los aparentes bio-antropólogos}

Al parecer, la ecología cultural en su insistencia por valorar a las comunidades humanas como poblaciones ajustadas al medio natural permaneció invariablemente sorda a algunas de las apreciaciones sociológicas básicas que Gordon Childe realizaba ya, desde su perspectiva ciertamente evolutiva, a principios del siglo Xx:

Aún en la Edad Paleolítica, el transporte de materiales por agentes humanos a grandes distancias de su origen natural (v. g., las conchas de moluscos transportadas desde el Océano Índico a Francia), también indica la posibilidad de un intercambio de ideas a través de regiones sumamente grandes. Desde la evolución neolítica la difusión de sustancias, artefactos inventos, símbolos de culto y objetos decorativos, entre las diversas sociedades que habitaron las diferentes partes de Europa y de Asia Menor, cuenta con abundante documentación arqueológica (Gordon Childe 1988, 42). 
Pese a esto, el carácter autista de la ecología cultural queda completamente exhibido y explicitado cuando Rappaport señala que la dinámica social de un grupo humano no sólo se encuentra regulada en un ambiente natural determinado, sino que se encuentra intrínsecamente autorregulada. Concebida como sistema cerrado, automático y autógeno, en el pensamiento de Rappaport la comunidad parece buscar mantenerse invariable (estable). De este modo, "un cambio en el valor de una variable da comienzo a un proceso que o bien limita un cambio ulterior o bien sitúa de nuevo el valor en su nivel inicial" (Rappaport $1987,4)$.

Al dejar de lado, o en segundo orden, los procesos intra e intersociales, nuestros aparentes bio-antropólogos pueden explicar, sin necesidad de seguir ningún análisis histórico-social, hechos humanos tan importantes como la dinámica interna de las comunidades, sus parentescos, alianzas y conflictos, sus relaciones "internacionales", las formas de trabajo, los rituales, sus instituciones, etc., haciendo referencia siempre al peso insoslayable del ambiente natural extrahumano (alma mater natura):

Del mismo modo que los termostatos se apagan y se encienden, afectando a la cantidad de calor producida por el horno y a la temperatura del medio, también los rituales de los tsembaga se inician y se completan, afectando el tamaño de la piara, a la cantidad de tierra cultivada, a la cantidad de trabajo empleada, a la frecuencia de las guerras y a otros componentes del sistema. Los programas que se deberían emprender para corregir la desviación de las variables respecto de sus límites aceptables vienen dados de antemano. Todo lo que hay que decidir es si se ha producido realmente una desviación. Los tsembaga llegan a tales decisiones a través de la discusión y de la posterior formación de un consenso (Rappaport 1987, 253).

El ritual, asumido en mi perspectiva como actualización de un hecho arquetípico ejemplar -un hecho eminentemente humano-socialque funda la identidad del grupo social (Eliade 1972, 54), es despojado por Rappaport de su universo ecuménico histórico simbólico sagrado y es colocado sobre un terreno llano y desmemoriado de vida rutinaria nítidamente pragmática. Prácticamente todo el proceso de interacción social-cuyos componentes todos pueden ser categorías mensurables 
para Rappaport en tamaños, cantidades, números, frecuencias, etcétera-, toda la dinámica social (el diálogo social) se basa según este autor, en un guión dictado por las condiciones del medio natural. Como si la gente sólo hablara de canículas y trojes.

\section{Estrategias adaptativas y cambio social}

A diferencia de los tres primeros autores que hemos revisado, Ángel Palerm (1998), Eric Wolf (1967, 1987), Brigitte Boehm Schoendube (1991, 2001, 2005, 2006), Jaime L. Espín Díaz (1983, 1987), Andrés Fábregas Puig (2009) y Pedro Tomé Martín (2005), entre otros, en sus estudios sobre el tándem sociedad-naturaleza, proponen comprender la relación entre ecosistema y dinámica social (cultura, economía, poder político) asumiendo a los espacios humanos como áreas histórico-políticas, donde hipotéticamente se genera el movimiento y la dialéctica social.

Tal consideración marca una diferencia sustancial con los anteriores enfoques, puesto que la unidad de análisis no puede ya presuponerse como geográfico-ambiental ni aislada, sino que se le reconoce como un "continuum diferenciado", una unidad ecológica, histórica y política cuya descripción debe ir "más allá de una presentación del escenario geográfico o del posibilismo ecológico" (Espín Díaz 1983, 5).

Sondeando las causas del resquebrajamiento del antiguo orden del mundo mesoamericano Wolf $(1967,102)$ refiere que "Las explicaciones de orden ecológico abren la vía a soluciones ulteriores, pero no podrían bastar: es necesario tener en cuenta las modificaciones que experimentó la estructura interna de la sociedad teocrática". Estos aportes me permiten distinguir en el seno de la perspectiva de la ecología cultural una incipiente metamorfosis en la concepción de lo que es la región o el espacio humano, donde se va del hábitat natural al área sociocultural, política ehistórica. Los trabajos de la Profesora Brigitte Boehm Schoendube constituyen uno de los ejemplos más acabados de esa conversión.

Sin embargo, y para citar un caso, autores como Espín Díaz (1983), al estudiar el fenómeno político en contextos territoriales amplios, consideran, siguiendo a Murra (1972), metodológicamente conveniente una subregionalización del área de acuerdo a la lógica ambiental y de explotación de los recursos. Esta subregionalización le permite al autor revi- 
sar las relaciones de poder en términos de división social del trabajo "que cierta especialización de las subregiones permite hacer" (Espín Díaz 1983, 97).

En la conformación de los grupos de poder locales, Espín Díaz introduce en su análisis un criterio ausente en los trabajos de autores como Rappaport -que centraron su trabajo en sociedades "primitivas"-: la influencia de un factor "externo", el Estado en este caso. El Estado mexicano se hace presente en la región purépecha a través de un megaproyecto de desarrollo subnacional instrumentado entre 1947 y 1977. Este proyecto, coordinado por la entonces Secretaría de Recursos Hidráulicos de México y operado a través de una comisión interinstitucional (Comisión del Río Balsas), formó parte de la política desarrollista del gobierno nacional impulsada entre las décadas de 1940 y 1970 (Ornelas Delgado 1993, 39-51).

Sin pretender dar un peso preponderante a la influencia del Estado en su área de estudio, Espín Díaz considera que su presencia y acción deben ser valoradas y especificadas en la configuración geopolítica regional $(1987,98)$. Y aunque parece importante la insistencia del autor en abordar las condiciones históricas concretas que ayudarían a entender la relación entre poder político y ambiente natural, al considerar necesario el enfoque de esta relación, sesga sus interpretaciones de lo intrínsecamente social

Al intentar conciliar la perspectiva convencional de la ecología cultural con un enfoque realmente histórico-social, Espín Díaz asume, al igual que Rappaport, que esa perspectiva ambiental-evolutiva es en sí ya "histórica", señalando un vínculo estrecho entre estrategias adaptativas y cambio social. No reconoce, como lo ha sugerido Wolf, la posibilidad de que no sean las condiciones del ambiente las que determinan lo histórico en la sociedad, es decir, los modos en que se conforma, varia y se comporta la sociedad y la manera en que ésta se relaciona con la naturaleza. Esta ambigüedad se lee claramente cuando Espín Díaz afirma que “[...] la relación actual de la población humana con su medio es el fruto de un aprendizaje continuado y penoso en el tiempo; por el resultado de experiencias anteriores, los hombres, a través de la cultura, han aprendido a dominar el ambiente, para hacer posible la vida y su reproducción constante" (Espín Díaz 1987, 100). 
¿El medio instruye y condiciona al ser humano o la cultura -el hombre en sociedad-determina los modos en que el ser humano se relaciona con la naturaleza? La cuestión no se precisa ni el autor se remite a algún caso específico que pudiera ilustrar alguna solución. Sí señala, pero sin diluir la ambigüedad, que su región de trabajo, "integrada, pero diferenciada en un marco de referencia histórica [...], constituye un sistema fuertemente condicionado por los bosques y por su transformación a través del trabajo humano" (Espín Díaz 1983, 26). De cualquier modo, Espín Díaz reconoce que existen hechos en las sociedades actuales que no son el resultado de procesos biogeográficos, sino que obedecen a otros mecanismos que exigen otra explicación que la "ambiental". Uno de estos hechos es precisamente lo político.

En la perspectiva marxista que asume Espín Díaz, lo político tiene una base o un trasfondo económico: el poder se mueve en el escenario económico. Y si bien lo económico define los modos en que el hombre se vincula con la naturaleza, lo económico y ese vínculo también están mediados por relaciones de poder. Finalmente coincido con Espín Díaz cuando señala, recordando a Gramsci, que lo político y lo económico "forman una unidad que es el fruto de un proceso cuyo agente exclusivo es la actividad humana en sus diferentes formas. Este proceso es la dialéctica histórica considerada en su totalidad" (1987, 103, cursivas mías).

Un taxón sociocultural

Haciendo una crítica general al enfoque de la ecología cultural, resulta notorio que sus estudios de socioecosistemas no superan el análisis funcional del "caso aislado", al considerar que el medio natural local, o en su caso global, afecta definitoriamente el universo sociocultural en comunidades humanas específicas. Con la ecología cultural, como señala Eric Wolf $(1987,32)$, "nos encontramos otra vez en un mundo de bolas de billar socioculturales que se desplazan en una mesa de billar universal", enfoque que ya desde finales de la década de los setenta del siglo Xx Ángel Palerm consideraba definitivamente superado $(1998,176)$.

Parafraseando a Wolf, puedo decir que para el enfoque convencional de la ecología cultural, la gente no tiene historia. Y aquí se dibuja claramente aún el sueño alucinado de aquella antropología que pretendía 
ver culturas prístinas por todas partes, en un mundo con más de quinientos años de interacción social, es decir, de conocimiento mutuo, de confrontaciones, amalgamientos, intercambios y acomodamientos. Señala Wolf:

Sin embargo, este concepto de una sociedad y cultura autónomas, autorreguladas y autojustificadas ha atrapado a la antropología dentro de los límites de sus propias definiciones. Dentro de los linderos de la ciencia se ha estrechado el alcance de la observación y del pensamiento, en tanto que afuera los habitantes del mundo van quedando cada vez más atrapados en el cambio general de alcance continental o mundial. ¿Puede decirse con verdad que alguna vez hubo un tiempo en que las poblaciones humanas existieron con independencia de las relaciones muy amplias, sin sufrir el influjo de grandes campos de fuerza? Del mismo modo que los sociólogos van tras el fuego fatuo del orden social y de la integración en un mundo de dislocaciones y cambios, así también los antropólogos buscan réplicas prístinas del pasado precapitalista y preindustrial en los sumideros y márgenes del mundo industrial y capitalista [...] Ambas (sociología y antropología) perpetúan ficciones que niegan los hechos de las relaciones y participaciones en marcha $(1987,33)$.

De este modo podemos comenzar a vislumbrar que no sólo el hombre colectivo y su cultura no son un simple producto pasivo de procesos naturales, sino que él se transforma a sí mismo transformando la naturaleza y transformando su cultura. El ser humano es esencialmente una especie sociocultural, no un sujeto animal cualquiera. "La especie humana es resultado de procesos naturales; al mismo tiempo, la especie es social por naturaleza" (Wolf 1987, 97). En suma, son las relaciones entre los seres humanos las determinantes de los modos de su ser social y no las relaciones sociedad-naturaleza. Sostener lo contrario es quedarse a la mitad del camino, es ver al hombre como a cualquier otra especie animal -y ninguna especie viva puede ser tratada "como cualquier otra espe-

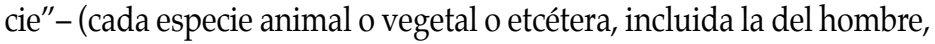
reclama su particularidad), olvidando que las relaciones sociales "conscientes" son las que finalmente ordenan los modos en que nos ocupamos del ambiente (habría que preguntarles a los platelmintos, por ejem- 
plo, si ellos no califican de conscientes sus propias relaciones sociales... ¿Se habrán preguntado los sociobiólogos si existió alguna vez entre los platelmintos una aferrada Juana de Arco, un pegajoso Nietzsche, un arquetípico Fortino Samano o un sensible Huitzilihuitzin? ¿Habrán ellos -los platelmintos- organizado alguna vez una intifada o un EZLN? No lo sé, pero en ocasiones descubro similitudes entre la clase cestodos y la clase humana burguesa y gobernante).

Cuando el ser humano extiende su mano hacia la naturaleza no lo hace para ver que obtiene de ella, él va por ella, realiza en ella su fin. A diferencia de, digamos, una hermosa y revoloteante gavilla de mariposas, los grupos humanos se apropian de su medio por medio de una acción elaborada, concertada socialmente, no por un mero impulso biológico-instintivo (habría que ver si ese impulso, orden o comando de las mariposas no tiene efectivamente un trasfondo social). Su iniciativa, la iniciativa del hombre, es una empresa no sólo colectiva, sino esencialmente social.

\section{Parnassius apollo}

Hablando de lepidópteros, y para ilustrar la confusión básica de los ecólogos culturales, señalemos que estos científicos sociales, naturalistas de lo social o bioantropólogos, no han tenido muy claro que las actividades y el ciclo de vida de hombres y animales se encuentran moldeados por distintos crisoles. A diferencia de los seres humanos, las mariposas están moldeadas por el crisol de Natura y se desenvuelven siempre "libremente" dentro de las infinitas posibilidades que ésta les ofrece.

Las pequeñas hadas a las que me refiero pueden criarse, por ejemplo, en una inmensidad de ambientes: dentro de una semilla; en un hormiguero, en simbiosis con feroces hormigas; parasitando una planta acuática, sumergidas a un metro de profundidad; en los tranquilos cementerios; dentro de una casa, cobijadas por las ropas del tatarabuelo; en lo nidos abandonados de los pájaros; en cortezas y maderos muertos; en hojas, ramas, troncos, tallos, arbustos, hierbas; en todos los estratos y rincones de un bosque; en terrenos baldíos y campos militares (sin militares y sin insecticidas, mejor) y así, en un inmenso e interminable etcétera (Leraut 1992). 
Infinitas posibilidades que, sin embargo, no cambian el hecho de que hasta una nube que cubra momentáneamente al sol modificará el comportamiento de estos seres alados. Delicados lepidópteros como la mariposa apolo (Parnassius apollo) (véase figura 1), reliquia boreo-alpina sobreviviente de las últimas glaciaciones, son muy sensibles al sol y se posan en la primer flor visible en cuanto una nube oscurece el cielo y sus orugas dejan de comer al crepúsculo vespertino. En otros casos, complejos procesos de asociación interespecífica como la homocromía y el habitus van acompañados de comportamientos instintivos curiosos: las especies asociadas "vuelan como las moscas a pleno sol, pero se dejan caer sobre los pedregales cuando una nube oscurece el cielo" (ibid., 65-66). Etcétera.

Figura 1. Parnassius apollo.

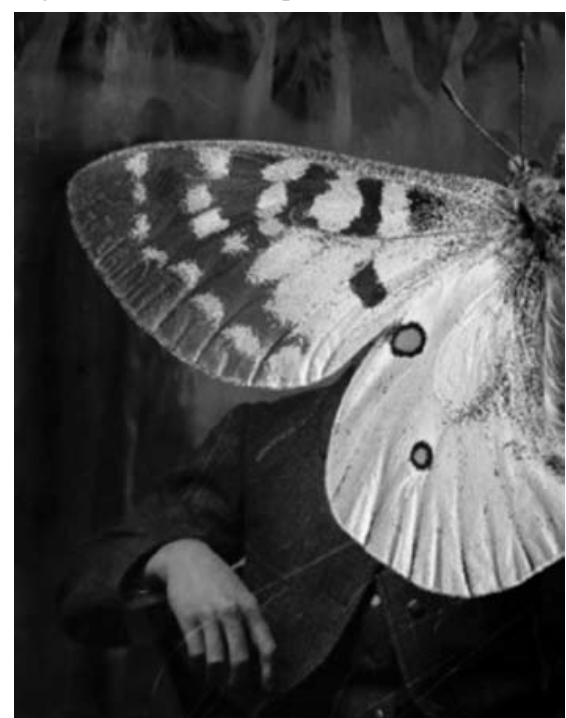

Jo Whaley, Parnassius apollo

Copyright $\odot 2007$

(Publicación autorizada por la artista

al articulista). 
Con los hombres no sucede lo mismo. El medio natural no determina la coreografía de la sociedad humana. El hombre colectivo, aunque dentro de la naturaleza (es también naturaleza), se desenvuelve a través de aquel crisol biológico que en definitiva no le presenta tantas posibilidades. O, dicho de otro modo, la especie humana es social por naturaleza. Siendo parte de él, el "molde" del género humano no es un entorno natural inconciente, es la sociedad (¿conciente?), y éste es el concepto que nos permite entender su relación con la naturaleza, no el de "adaptación". Este apunte es claramente explicitado por Karl Marx en los siguientes términos: "El animal es inmediatamente uno con su actividad vital. No se distingue de ella. Es ella. El hombre hace de su actividad vital misma objeto de su voluntad y de su conciencia. Tiene actividad vital conciente. [...] La actividad vital conciente distingue inmediatamente al hombre de la actividad vital animal" (Marx 2001a, 112).

El conocimiento y la cultura, las actividades concientes del hombre, son una función epistémica (científica o panontológica), es decir, sociocultural e histórica, y no meramente reactivas al medio natural. Ángel Palerm prefiere expresar esta idea afirmando que "el éxito de la especie biológica humana es el triunfo de la cultura y de la diversificación y transformación de las formas culturales" (Palerm 1998, 175-176). Sin embargo, ¿quiere decir esto que la ecología no puede explicar lo social humano? No, lo que quiero decir es que el concepto de ecología ha sido truncado en la perspectiva de la ecología cultural tradicional, sesgado y trastocando de este modo también su análisis de lo social.

\section{Interludio}

La crítica general al enfoque de la ecología cultural realizada en el apartado anterior se dirige más a los ejes conceptuales centrales que articulan su aparato teórico-metodológico que a la revisión exhaustiva de la obra de los autores que aquí se citan. El principal de estos ejes, el más claro y simple, y por ende el más fácilmente criticable, se refiere a la relación causal entre medio natural y desarrollo cultural. En esta corriente he ubicado las perspectivas analíticas de Rappaport (1987), Adams (1978) y Harris (1993), caracterizadas por otorgar un peso definitorio a las condiciones del medio natural sobre la manera en que se organiza la 
sociedad (determinismo ambiental). El segundo eje conceptual de la ecología cultural, el posibilismo, considera que el medio natural no determina pero si condiciona la forma en que se desenvuelve la sociedad que lo ocupa, es decir, "[...] hay una dependencia recíproca entre cultura y entorno. La cultura tiene, en su confrontación con el medio ambiente, la posibilidad de escoger" (Storå 1994, 3), Aquí ubico las perspectivas de autores como Espín Díaz $(1983,1987)$.

El tercero y último de estos ejes centrales es el denominado interaccionismo, que trata de salvar la supuesta dependencia del quehacer humano con respecto a las condiciones de su entorno biofísico no humano, asumiendo que hombre y entorno se condicionan mutuamente. Esta perspectiva me parece legible también en los trabajos de Espín Díaz cuando define a la región como un sistema condicionado por el medio (bosque) y por el trabajo humano. Lo mismo que estos tres ejes supracitados, los desarrollos subsecuentes de la ecología cultural expuestos por Storå (1994) (enfoque ecosistémico, materialismo cultural y etnoecología) siguen sin plantearse puntualmente dos cuestionamientos fundamentales: 1. ¿Qué es ecología? Si no se define esto, entonces cualquier cosa podría hacerse a su nombre. 2. ¿Son el mundo y la naturaleza una realidad externa a la sociedad, es decir, al ser humano? Al parecer, el parcelamiento de la realidad es un recurso (no siempre adecuado) que hace al ser social ordinario.

Asumir que el ser humano no se comporta como los cerdos o las mariposas, que la interacción sociedad-naturaleza es un asunto del cariz que toma la interacción humana, me lleva a precisar en el apartado siguiente la designación estricta del concepto de ecología, además de los de sociedad y socioecología.

\section{CONCEPTOS Y ENFOQUeS CLAVE DEL ANÁLISIS SOCIOECOLÓGICO}

\section{Introito}

La dura metamorfosis de la ecología cultural, que va pasando del estudio de culturas supuestamente prístinas y aisladas, condicionadas en su ser social por el ambiente "externo", hacia esquemas de explicación his- 
tórico-social y económico-políticos suprabiológicos, está revirtiendo su tesis de la preponderancia del medio duro (físico, biológico, natural; predeterminado [asumido, ya sea como espantosamente ordenado, como tormentosamente arbitrario o como la unidad de ambas monstruosidades], condicionante, limitado) -regido por ingobernables y apenas comprensibles leyes y procesos estocásticos, genéticos, biofísicos, termodinámicos, tróficos y geoclimáticos-sobre el medio ecuménico. Es el ser social humano, la sociedad-cuerpo sólido y consistente, aunque naturalmente dinámico, dialéctico, flexible, cambiante, fluido; volátil, volitivo y emocional; rico en coherencia pero también lleno de inquietudes, de ensueños, pesadillas y presagios, de "malestares" y fiebres alucinantes; ente andante saturado de conflicto, espontaneidad y creatividad y destructividad humana, colectiva e individual- lo que hace avanzar al hombre hacia el conocimiento de sí, de su entorno socionatural. Estas consideraciones plantean la necesidad de precisar los conceptos fundamentales de la perspectiva ecocultural que, bajo tal recomposición y salvando el uso antiestético de limitantes categorías parcelarias como la de "ecología cultural política" (que no tardará en querer llamarse "ecología cultural económica política..."), aquí llamo socioecología.

No ha dejado de llamarme la atención el hecho de que los científicos sociales que reviso en el capítulo anterior, inscritos dentro del espíritu de la ecología cultural, desatiendan la tarea básica de discutir y conocer, y por lo tanto de asumir o al menos de comprender, la definición y el alcance cabal de uno de los conceptos fundamentales que retoman de las ciencias naturales y utilizan para identificar su perspectiva analítica. Este concepto es el de ecología.

En el presente apartado trato de dar respuesta no sólo al cuestionamiento básico de lo qué es la ecología, sino también a una serie de interrogantes elementales que nos permitirá avanzar sobre un terreno más firme en la indagatoria de las relaciones sociedad-naturaleza. ¿De qué está hecha una sociedad humana? ¿Cuáles son los presupuestos de un estudio de carácter socioecológico? ¿Sociedad y Naturaleza son categorías contrapuestas? ¿Puede la perspectiva socioecológica abordar categorías de análisis sociopolítico tales como el poder? El propósito es esclarecer, a partir de la somera revisión que he hecho de los presupuestos de la ecología cultural, las coordenadas conceptuales que orienten el 
desarrollo de investigaciones ulteriores en el campo de la ciencia del hombre-la sociología o la antropología o la ecología o lo que sea-.

Ecología

Para acercarnos al concepto de "ecología" veamos cómo definen su disciplina algunos ecólogos. En primer lugar, Ramón Margalef (1998) nos recuerda que fue el biólogo alemán Ernst H. Haeckel quien en 1869 propuso el término "ecología" para referirse al estudio de las relaciones de un organismo con su ambiente inorgánico u orgánico. Ya desde su comienzo, la ecología reconocía al conocimiento de las interacciones de los organismos entre sí, a la dinámica de poblaciones, como el fundamento de su ciencia y la característica del mundo dinámico. A partir de este momento "todas las definiciones de ecología, o las más de ellas, en síntesis, vienen a decir que la ecología estudia las relaciones recíprocas entre el medio y los organismos, o entre los organismos entre si" (Margalef 1998, 2).

Eugene P. Odum (1993) por su parte señala que el interés de la ecología va más allá del estudio de los organismos como individuos. Esta ciencia se interesa, señala el autor, más por los sistemas-población y sistemas-comunidad que por los sistemas genéticos, celulares u orgánicos. Sin embargo, aunque se ocupa del estudio de los sistemas macroscópi$\cos$, la ecología no descuida los de mayor escala. Atiende, por decirlo al modo del autor, a la "familia íntegra" (Odum 1993, 11 y ss).

Al señalar que la ecología puede considerarse también como el estudio de la estructura y función de la naturaleza, Odum subraya en todo momento que la humanidad es parte de esta última. De este modo, la ecología ha ido avanzando "[...] de una división de las ciencias biológicas (donde se le asumía como una biología del medio natural) hasta ser una ciencia principal interdisciplinaria que agrupa a las ciencias biológicas, físicas y sociales" (Odum 1993, 12).

En este mismo sentido, Margalef considera que la ecología es "la biología de los ecosistemas" (Margalef 1998, 2), entendiendo al ecosistema como a una red de individuos de muchas especies en el seno de un ambiente de características definibles. Estas especies están implicadas en un proceso dinámico e incesante de interacción, ajuste y regulación. 
Así, para este ecólogo español la palabra "ecosistema" no se usa en el sentido de unidad concreta, sino de nivel de organización (ibid., 2).

Afirmaciones de tal magnitud conducirín a la ciencia ecológica, una ciencia de lo intrincado, a universos de estudio de inconmensurable, sino que imposible, explicación; a menos que la población humana -una población cuya inteligencia autorreflexiva forma parte de la sutil y admirable inteligencia de Natura- sea considerada como una población diferente no sólo en especie, sino sui generis (una población que siendo parte de "ambientes de características definibles" y ecosistemas, los trasciende -en ocasiones los rompe-porque su dinámica natural está gobernada por procesos supra o transbiológicos [estúdiese el ascetismo])

La ecología es, entonces, la ciencia que estudia interacciones. Pero, como hemos visto, no sólo es el estudio de las interacciones de los organismos con su medio, tal y como lo asumió la ecología cultural con los hombres y la naturaleza. Es fundamentalmente el estudio de las interacciones entre los organismos mismos y entre grupos de organismos (poblaciones), ya que estas interacciones son las que determinan finalmente su relación con el entorno. Incluso el proceso de "adaptación" al ambiente está determinado por las interacciones de los organismos entre sí. A este respecto Amos H. Hawley señala que hay algunas lecciones de la ecología que los científicos sociales necesitan aprender bien, entre ellas, que:

[...] una relación que funcione con el medio ambiente se alcanza no por individuos e incluso especies que actúan independientemente, sino mediante una actividad concertada a través de una organización de sus diversas capacidades; es decir, constituyendo un sistema comunal. La adaptación se considera como un proceso colectivo más que individual" (Hawley 1991, 25).

Es preciso subrayar que incluso desde el punto de vista puramente biológico referido a toda clase de organismos vivos, desde los más sencillos hasta los más complejos, e independientemente de su reino (animal o vegetal), todos ellos son producto de su historia social y no simples objetos independientes y pasivos amoldados por las fuerzas inexpugnables del entorno. Lo que ha realizado la ecología cultural, salvo los trabajos más recientes que están intentando trascender su enfoque tradicional, son estudios de carácter autoecológico y biogeográfico. La 
autoecología es una especie de "fisiología al aire libre" (Margaler 1998, 2) que trata de explicar por qué determinada especie puede vivir en un lugar dado y saber cómo responden los organismos a las características del medio. El resultado es que las diversas especies manifiestan determinados síndromes de adaptación (Ibid., 2).

El error grave de la ecología cultural ha sido querer explicar los rasgos específicos de una sociedad humana, su cultura, como meros "síndromes de adaptación". En otras palabras, su error consistió en tratar a la sociedad como una comunidad animal o vegetal. Incluso tratada así, como una comunidad no humana, la ecología cultural no la estudió desde un punto de vista ciertamente ecológico sino autoecológico; y junto a este último, conjugó el enfoque biogeográfico, entendido como intento por explicar cómo una especie (no humana) ha logrado colonizar un determinado lugar.

Vemos así que desde una perspectiva ciertamente ecológica, un entendimiento de las relaciones sociedad-naturaleza exige previamente un conocimiento riguroso del sistema social humano. Por lo tanto y en contraposición a lo sugerido por Pacheco Muñoz $(2005$, 32), consideramos pertinente que el sistema social humano sea estudiado por la ecología, en cuanto que este sistema forma parte de la "familia integral" de Gea; y más aún, en cuanto que está constituido por sujetos-en-relación. De este modo estaremos hablando en adelante de estudios de carácter socioecológico.

\section{Socioecología}

El enfoque socioecológico que propongo discute ideas planteadas por la sociología, la antropología, la ecología, la ecología humana, la teoría de sistemas, la geografía histórica y el sentido común, entre otros esfuerzos encaminados a la comprensión del comportamiento del ser humano. ¿Se trata de vislumbrar cómo las sociedades que el hombre constituye le han dado forma humana al mundo o el hombre es simplemente naturaleza conflictuada y autorreflexiva? Ideas diversas ahora son discutidas desde diversos ámbitos del quehacer científico. Ejemplos de estos ámbitos pueden ser la etnoecología (Conklin 1963), la llamada "agroecolo- 
gía", que en países como México se ha orientado en parte hacia la comprensión de las relaciones existentes entre saber humano y naturaleza (Venegas Pérez 1996) o la "historia ambiental", cuyo pensamiento se interesa en el análisis del cambio ambiental y su relación con las actividades humanas (Leal 2002; Juárez Flores 2005).

Estas tendencias centran su trabajo en el estudio de las sociedades y sus procesos internos (por ejemplo, en sus cosmovisiones y conflictos) como factor determinante de los modos en que el hombre se relaciona con la naturaleza. Asumir lo anterior no descarta por supuesto el hecho de que las condiciones ambientales, aunque no determinan nunca las formas consensuadas de organización social ni su dinámica intrínseca, si fomentan y potencian algunas de sus actividades, orientaciones y relaciones (Wittfogel 1956).

Desde el enfoque socioecológico, la crítica a la idea de naturaleza virgen, prístina, autónoma y ajena a la existencia de las sociedades humanas, sustenta la posición de considerar que la política pública de "preservación" de la naturaleza bajo el esquema de la "áreas naturales protegidas" promovida por los Estados nacionales modernos se equivoca al suponer que la sociedad ha existido y puede existir apartada de ella, o a la inversa. Este punto incluso invita a minar la idea misma de la existencia de un "medio ambiente" para la sociedad. Sociedad y ambiente son uno solo. Este asunto de carácter epistemológico ha sido ya discutido en obras como la de Philippe Descola y Gísli Pálsson (2001) y Karl Marx (2001a). El "entorno natural", en su simpleza o complejidad, en su lógica mágica o científica, es una construcción del intelecto, es decir, es una idea, una creación, un producto social humano.

En un nivel conceptual, la naturaleza forma parte del hombre en tanto que "[...] las plantas, los animales, las piedras, el aire, la luz, etc., constituyen teóricamente una parte de la conciencia humana [...]" (Marx 2001a, 111); y en un nivel práctico, en tanto que "físicamente el hombre vive sólo de estos productos naturales, aparezcan en forma de alimentación, calefacción, vestido, vivienda, etcétera" (ibid., 111). Sin embargo, no quiero decir con esto que el mundo sea humano. El hombre es una pequeña parte del mundo (cualquier componente específico del mundo concreto es una pequeña parte de él) y el mundo es mundo a su manera, con y sin nosotros. La idea que tengamos del mundo es fi- 
nalmente sólo una perspectiva: la diversa y variante perspectiva humana del mundo vasto.

A propósito de este último apunte, me parece bella estéticamente y lúcida científicamente la perspectiva que del mundo alcanza la ecología cultural en el pensamiento de Brigitte Boehm Schoendube $(2001,2006)$. A mi parecer, sus estudios sobre historia ecológica y lectura del paisaje cultural se deslizan ya sobre ámbitos del quehacer socioecológico. En última instancia estoy también de acuerdo con Boehm Schoendube en que "no es a Steward a quien haya que culpar de que la ecología cultural siguiera senderos particularizantes y ecológicamente deterministas en el estudio de la "adaptación cultural" al medio de grupos humanos aislados" (Boehm Schoendube 2001, 66).

También algunas apreciaciones, no siempre bien escuchadas por los ecólogos culturales y por analistas regionales contemporáneos, de Vidal de la Blache, pilar del desarrollo de la geografía histórica, apuntan en la dirección de la integración holística de lo humano y el mundo físico o natural:

Los agrupamientos parciales, por regiones o partes del mundo, tienen su sentido y su razón de ser, pero no reflejan más que imperfectamente la sola unidad de orden superior que tenga una existencia sin fraccionamiento ni restricción. [...] La explicación no pertenece más que a la tierra tomada en su conjunto. Por encima de mil combinaciones que hacen variar hasta el infinito la fisonomía de las comarcas, hay condiciones generales de formas, de movimientos, de extensión, de posición, de intercambios que restablecen sin cesar la idea de la tierra. Los estudios locales, cuando se inspiran en este principio de generalidad superior, adquieren un sentido y un alcance que supera en mucho el caso particular que enfocan (Manduca Carlomagno 2004, x).

Profundizado en este tema, Marx señala que la naturaleza es el "cuerpo" del hombre puesto que requiere de ella para vivir (2001a, 112). La vida íntegra del hombre (física y espiritual) se encuentra ligada a la naturaleza, es decir, "la naturaleza esta ligada consigo misma, pues el hombre es una parte de la naturaleza" (ibid., 112). El círculo conceptual de la unidad epistemológica sociedad-naturaleza se cierra cuando reconocemos nuevamente que la naturaleza (el mundo que pensamos y vivimos), el 
medio natural, es un concepto formal, una categoría heurística social que, estando dentro de la cabeza del hombre, sale en nociones tales como sol, padre, fuego, abuelo, luna, madre vieja, etc. En esta dirección ya no tendría sentido hablar de "relaciones" sociedad-naturaleza: los polos han desaparecido. En un sentido más amplio, el mundo, complejo o sencillo, el mundo que pensamos - pensamiento nacido del intercambio sociocultural-es un campo definido por contornos de origen humano sociohistórico. Por otra parte es pertinente señalar que el enfoque que aquí denomino "socioecológico" se opone a la idea planteada por la "sociobiología" en el sentido de que es en los genes en donde podemos encontrar al menos las líneas generales que rigen el comportamiento de los seres humanos, de manera que la cultura se encontraría, en última instancia, sometida a las leyes de la genética y la biología molecular (Muñoz Rubio 2005). La socioecología fundamenta su análisis de la sociedad y su cultura en, y la explica desde, las interacciones humanas, concibiendo al mundo formal como entramado de relaciones sociales.

Citando a Muñoz Rubio $(2005,4)$, coincido en que: "el ser humano es el conjunto de sus actividades sociales y que éstas a su vez son las que constituyen a cada individuo, a la humanidad toda y a sus sectores: clases, razas, etcétera. [...] diríase que nada tiene sentido en el ser humano si no es a la luz de sus relaciones sociales". Por supuesto que éstas no son ideas nuevas, pero al parecer la ciencia social llega a perderlas de vista cuando hace uso desatento de conceptos y categorías de análisis de las ciencias naturales (ecología) o cibernéticas (sistema).

Recapitulando, vemos ya que la idea de "ecología" con la que se pretendía explicar la sociedad desde la ecología cultural centraba su interés en el estudio de la influencia del entorno natural sobre la conformación y comportamiento de los grupos humanos, concediéndole al entorno físico-natural un papel preponderante en la definición de sus rasgos sociales básicos (económicos, políticos y culturales). Éstos, como decía, en realidad no fueron estudios de carácter ecológico sino autoecológico y biogeográfico. No se aplicó de manera íntegra el concepto de ecología, tal y como lo he recuperado aquí de su fuente disciplinar.

He señalado que la ecología en sí no es el estudio de las relaciones de los seres vivos con su medio natural. Esto sería sólo su aspecto de segundo orden y concederle demasiado peso denota la influencia del evolucio- 
nismo que sostiene la idea de la adaptación al ambiente como condición de sobrevivencia de los organismos. ¿Puede esta idea ser válida para los grupos humanos? Señalo que no, que desde un punto de vista efectivamente ecológico esa consideración no puede siquiera aplicarse a los organismos vivos no humanos.

El fundamento de las relaciones que se establecen entre los organismos de una especie determinada y su ambiente es la interacción ordinaria existente entre los organismos mismos de dicha especie y de esta especie con otras. Son las relaciones específicas que se establecen entre los individuos y sus poblaciones las que definen una acción colectiva, concertada socialmente, hacia el medio que conforman. Pensar que la dinámica de la sociedad humana puede explicarse sólo como un impulso de adaptación al medio natural es insostenible (incluso para organismos como las amibas). Es necesario comprender la dinámica interna de sus poblaciones para explicar sus relaciones con el "entorno". Esto es de lo que en primer orden se ocupa la ecología.

\section{La sociedad: entramado de operaciones sociales}

De acuerdo con el sociólogo norteamericano C. Wright Mills, el análisis sociológico se plantea fundamentalmente tres tipos de preguntas: 1 . ¿Cómo está conformada una sociedad? 2. ¿Qué lugar ocupa esta sociedad en la historia? 3. ¿Qué variedad de seres humanos concretos caracterizan esta sociedad? (Mills 1997, 40). El primer cuestionamiento es abordado aquí desde un nivel básico: ¿Qué es una sociedad? ¿De qué está hecha una sociedad? Un conjunto de hombres, es decir, un grupo de personas ocupando un espacio delimitado sin interacción mutua, sin comunicación ¿puede considerarse una "sociedad"? Los cuestionamientos 2 y 3 serán abordados en un trabajo posterior.

En la tradición sociológica la sociedad es comprendida básicamente como agregado de hombres circunscrito a un espacio determinado. Agregado al que luego se le asigna cierto tipo de atributos y funciones. Esta idea proviene desde el nacimiento mismo de la sociología, cuando Auguste Comte dividió el sistema de su teoría en "estática social" y "dinámica social", denominadas luego por Herbert Spencer como "estructuras" y "funciones" sociales (Sztompka 1995, 25-26). 
Sin embargo, bajo la perspectiva socioecológica la sociedad aparece compuesta de otro modo. Está hecha de relaciones intencionadas. Karl Marx (2001:50) nos ayuda a ilustrar esta idea cuando afirma que la sociedad es "una rica totalidad con múltiples determinaciones y relaciones". De hecho, y siguiendo a este autor, todo está hecho de procesos, y son estos los que se deben estudiar para comprender "lo concreto": "[...] lo concreto es concreto porque es la síntesis de múltiples determinaciones, por lo tanto, unidad de lo diverso. Aparece en el pensamiento como proceso de síntesis, como resultado, no como punto de partida [...] [Así] las determinaciones abstractas conducen a la reproducción de lo concreto por el camino del pensamiento" (Marx 2001, 51).

El método lógico-histórico marxiano de crítica de la economía política parte del análisis de una relación. Señala Fredrich Engels (Marx 2001, 104) que con ese método, luego de identificada la relación económica, se procede a estudiar cada uno de los lados que la integran, de donde se deduce su relación recíproca y su interacción. Añade que:

La economía política comienza por la mercancía, por el momento en que se cambian unos productos por otros [...] El producto que entra en el intercambio es una mercancía. Pero lo que le convierte en mercancía es, pura y simplemente, el hecho de que a la cosa, al producto, vaya ligada una relación entre dos personas o comunidades [...] La economía no trata de cosas, sino de relaciones entre personas, y, en última instancia, entre clases; si bien estas relaciones van siempre unidas a cosas y aparecen como cosas (ibid., 106).

Del mismo modo, Max Weber $(1944,5)$ delinea una idea de sociedad basada en relaciones que él denomina "acciones sociales". Estas acciones deben enlazar a ellas un sentido subjetivo, por tanto, son acciones en donde su sentido está referido y orientado por otras acciones. Explicitando, el autor señala que:

No decimos en modo alguno que en un caso concreto los partícipes en la acción mutuamente referida pongan el mismo sentido en esa acción, o que adopten en su intimidad la actitud de la otra parte, es decir, que exista "reciprocidad" en el sentido [...] Empero (la relación social) no deja de estar referida en la medida en que el autor presupone una determinada actitud de su contrario frente a él [...] (Weber 1944, 22). 
Así, por "relación social" puede entenderse una conducta plural recíprocamente referida orientada por esa correlación. Para el sociólogo de Heildelberg, la relación consiste en la probabilidad de que se actuará socialmente en una forma "indicable", y el contenido de la relación puede ir desde el conflicto, la sinergia, el intercambio mercantil y la competencia, etcétera; y ser de clase, de comunidad nacional, etcétera. Este contenido, sin embargo, como ya explicaba Weber, no es necesariamente percibido de igual manera por los partícipes de esta reciprocidad: el sentido de la relación puede ser diferente para cada uno de ellos. De hecho, una acción social (relación) apoyada en actitudes que signifiquen una correspondencia de sentido pleno y sin residuos es en la realidad un caso límite (Weber 1944, 24).

Además, señala Weber que una relación social puede ser de carácter transitorio (no necesariamente única e irrepetible) o permanente (no necesariamente continua) y que no necesariamente mantiene su sentido con el transcurso del tiempo; puede variar, por ejemplo, de la cooperación a la confrontación. La relación social, en cuanto forma singular de acción social (acción individual o colectiva orientada por la(s) acción(es) de otro(s), es decir, orientada por el sentido contenido en la acción reciproca), puede estar también determinada por expectativas, por valores, por emociones o por una costumbre arraigada $(1944,20)$.

Siguiendo las apreciaciones weberianas, Niklas Luhmann $(1998,81)$ subraya que la sociedad se compone de "operaciones selectivas". Se trata de interacciones no arbitrarias en las que subyace una decisión de presentación ante el otro, es decir, la sociedad es comunicación. De este modo, entendida como proceso de interacción, la sociedad, conformada por transcursos histórico-sociales específicos, puede ser explicada por la ecología que estudia fundamentalmente interacciones, enfoque que sin ser nuevo en el ámbito de las ciencias sociales no ha sido empleado de manera adecuada, como hemos visto. Por lo tanto, la perspectiva ecocultural debe ocuparse, siguiendo los procedimientos netamente ecológicos, en primer término del estudio de las interacciones entre los seres humanos mismos para poder explicar después las relaciones de los grupos humanos con la naturaleza. La desatención a este orden ha sido la debilidad cardinal que han adolecido la mayoría de los estudios de ecología cultural que conozco. 
La reorientación de la idea central de la ecología cultural, basada corrientemente en el determinismo ambiental de la dinámica social, hacia perspectivas de carácter socioecológico que ubiquen su análisis en la preponderancia efectiva de las relaciones sociales como factor determinante en la conformación de lo social y de los vínculos que las sociedades establecen con la naturaleza, contribuirá al replanteamiento del concepto de sociedad y a la operación adecuada del término de ecología (véase cuadro 2).

Cuadro 2. Desarrollo conceptual de la ecología cultural

\begin{tabular}{|c|c|}
\hline Perspectiva convencional & Enfoque socioecológico \\
\hline $\begin{array}{l}\text { - La ecología se entiende como el } \\
\text { estudio de las relaciones entre los } \\
\text { organismos y el medio ambiente } \\
\text { (autoecología y biogeografía). } \\
\text { - El ambiente-entorno local natural } \\
\text { es determinante de lo social. } \\
\text { - Cultura = síndrome de adapta- } \\
\text { ción. } \\
\text { - Análisis de socio-ecosistemas } \\
\text { supuestamente aislados y } \\
\text { autorregulados. } \\
\text { - Las sociedades = "bolas de billar" } \\
\text { socioculturales. } \\
\text { - La gente no tiene historia social; } \\
\text { su "historia” es ambiental. } \\
\text { - La sociedad se encuentra } \\
\text { insertada en la naturaleza o, en } \\
\text { otro extremo, sociedad y } \\
\text { naturaleza son mundos } \\
\text { separados. }\end{array}$ & $\begin{array}{l}\text { - La ecología estudia en primer orden la } \\
\text { dinámica interna de poblaciones y } \\
\text { sociedades. En segundo orden, y basado en } \\
\text { lo anterior, explica las relaciones entre } \\
\text { sociedad y entorno. } \\
\text { - El entorno del hombre es el ambiente } \\
\text { ecuménico-social. } \\
\text { - Cultura = entramado de relaciones sociales. } \\
\text { - Un entendimiento de las relaciones } \\
\text { Sociedad-Naturaleza requiere un conoci- } \\
\text { miento de las relaciones sociales humanas. } \\
\text { - La sociedad humana no es producto ni del } \\
\text { ambiente físico, ni de leyes genéticas ni } \\
\text { biológicas. } \\
\text { - La sociedad se explica desde las relaciones } \\
\text { sociales. } \\
\text { - Las sociedades establecen relaciones entre } \\
\text { sí (local, continental y globalmente). } \\
\text { - El molde del género humano es la sociedad. } \\
\text { - La sociedad es un entramado de operacio- } \\
\text { nes sociales. } \\
\text { - Sociedad y naturaleza no están separadas. }\end{array}$ \\
\hline
\end{tabular}

Fuente: Elaboración propia, con base en Gordon Childe (1988); Steward (1955), Rappaport (1987), Adams (1978), Harris (1993), Espín Díaz (1983, 1987), Boehm Schoendube (1991, 2001, 2005, 2006), Marx (2001, 2001a), Weber (1944), Luhmann (1998), Wolf (1987), Hawley (1991), Margalef (1998) y Odum (1993). 
Esta nueva perspectiva reforzará el enfoque social científico que dilucida las relaciones sociales -la sociedad-, sus intereses y artificios, como fundamento sobre el cual se generan y establecen las culturas, el conocimiento, los conflictos, la tecnología, las instituciones, el trabajo y todos sus procesos específicos. En suma, contribuirá al reconocimiento de que la sociedad es un proceso de relaciones humanas concretas determinado históricamente y del cual forman parte los modos, muchas veces contrapuestos, en que el hombre concibe y maneja el mundo.

\section{CONCLUSIÓN}

Las implicaciones metodológicas del enfoque socioecológico descrito, precisados los conceptos de ecología y sociedad, establecen que el desarrollo de sus investigaciones se centren, primero, en la dinámica sociohistórica que define formas particulares de relación social; segundo, en la forma celular en que estas relaciones sociales operan y se desenvuelven actualmente y; tercero, basado en lo anterior, explicar el carácter del vínculo, derivado del tipo de interacción humana, que los grupos humanos establecen con su medio (ecuménico y biofísico) específico.

De este modo, la socioecología que aquí propongo invierte el enfoque tradicional de la ecología cultural. No considero ya que sea del ambiente natural extrahumano de donde le viene a la sociedad su condicionante de ser. Es el ser sociocultural intrahumano sensible, pujante, pugnante y pensante lo que hace avanzar al hombre de una forma determinada en su contexto (natural y social). Este enfoque con sus implicaciones heurísticas es aplicado en una investigación que he realizado en la región del volcán La Malinche (Granados Campos 2009), y que estudia una forma vital de relación social y su vínculo con los modos en que el hombre se relaciona con la naturaleza: la relación de poder.

\section{BibLIOGRAFÍA}

ADAms, Richard N., La red de la expansión humana, México, Centro de Investigaciones Superiores del INAH, Ediciones de la Casa Chata, 1978.

Boehm De LameIRAs, Brigitte, “El Estado en Mesoamérica. Estudio sobre su 
origen y evolución", Revista Española de Antropología Americana, núm. 21, Madrid, Universidad Complutense de Madrid, 1991, 11-51.

, "El lago de Chapala: su rivera norte, un ensayo de lectura del paisaje cultural", Relaciones, núm. 85, vol. XXII, invierno, Zamora, México, El Colegio de Michoacán, 2001, 57-84.

, "Buscando hacer ciencia social. La antropología y la ecología cultural", Relaciones. núm. 102, vol. XXVI, primavera, Zamora, México, El Colegio de Michoacán, 2005, 62-128.

- Historia ecológica de la cuenca de Chapala, Zamora, México, El Colegio de Michoacán, 2006.

ConkLIN, Harold C., El estudio del cultivo de roza, Washington, Unión Panamericana, 1963.

Descola, Philippe y Gísli Palsson, Naturaleza y sociedad: perspectivas antropológicas, México, Siglo Veintiuno Editores, 2001.

DuRAND, Leticia, "La relación ambiente-cultura en antropología: recuento y perspectivas", Nueva Antropología, núm. 61, vol. xvIII, septiembre, México, Nueva Antropología, 169-184.

ELIADE, Mircea, Tratado de historia de las religiones, México, Ediciones Era, 1972.

Espín DíAZ, Jaime, “La región de Uruapan: criterios de definición y características ecológicas", Relaciones, núm. 14, vol. Iv, primavera, Zamora, El Colegio de Michoacán, 1983, 5-30.

, "Poder y ecología: el área de influencia de Uruapan" en Guillermo de la Peña (comp.), Antropología social de la región purépecha, Zamora, El Colegio de Michoacán, 1987, 97-132.

FÁBREGAS PUIG, Andrés, "La ecología cultural política y el estudio de regiones en México", Revista de Dialectología y Tradiciones Populares, núm. 1, vol. LXIV, enero-junio 2009, 167-176.

GonzÁlez Jácome, Alba y Silvia Del Amo RodríGuez (comps.), Agricultura y sociedad en México. Diversidad, enfoques, estudios de caso, México, Universidad Iberoamericana/Editorial Plaza y Valdés, 1999.

GoRdon ChILdE, Vere, Evolución Social, México, unAm/Plaza y Valdés, $2^{\mathrm{a}}$ edición, 1988.

Granados Campos, Luis Roberto, "El bosque en llamas. Poder y naturaleza en la región del volcán La Malinche", tesis de maestría, CIISDERUniversidad Autónoma de Tlaxcala, México, 2009. 
HARRIS, Marvin, Canibales y reyes. Los orígenes de las culturas, Barcelona, Librería Editorial Argos, 1978.

Jefes, cabecillas, abusones, México, Alianza Editorial, 1993.

HAwleY, Amos H., Teoría de la ecología humana, España, Editorial Tecnos, 1991.

JUÁREZ FLORES, José Juan, “Malintzi Matlalcuéyetl: Bosques, alumbrado público y conflicto social en la desarticulación de un entorno ecológico (Puebla-Tlaxcala, 1760-1870)", Tesis de Maestría en Historia, México, Universidad Autónoma Metropolitana-Iztapalapa, 2005.

LeAL, Claudia, "La naturaleza en los estudios sociales", Repensando la Naturaleza. Encuentros y desencuentros disciplinarios en torno a lo ambiental, Germán Palacio y Astrid Ulloa, eds., Medellín, Universidad Nacional de Colombia, 2002, 123-137.

LeRAUt, Patrice, Las mariposas en su medio, Barcelona, Plural de Ediciones, 1992.

Luhmann, Niklas, Teoría de los sistemas sociales (artículos), México, Universidad Iberoamericana, 1998.

Margalef, Ramón, Ecología, Barcelona, Ediciones Omega, 1998.

MARX, Karl, Introducción general a la crítica de la economía política/1857, México, Siglo Veintiuno Editores, 26 a edición, 2001.

___, Manuscritos de economía y filosofía, España, Alianza Editorial, 2001a.

Mills, C. Wright, La imaginación sociológica, México, Fondo de Cultura Económica, $2^{a}$ edición, 1997.

MuÑoz RuBio, Julio, “Naturaleza humana y sociobiología”, Memoria virtual, núm. 201, noviembre 2005 (disponible en: http:/ / memoria. com.mx/201), [consulta: abril 2008].

MuRRA, John, La organización económica del Estado inca, México, Editorial Siglo XXI, 1972.

Odum, Eugene P., Ecología, México, CECSA, 1993.

ORNELAS DeLGADO, Jaime, Estructuración del territorio y política regional en México, México, Universidad Autónoma de Tlaxcala, 1993.

ORTNER, Sherry B., La teoría antropológica desde los años sesenta, México, Editorial Universidad de Guadalajara, 1993.

PACHECO MuÑoz, Miguel Fernando, "El ambiente, más allá de la naturaleza", Elementos: Ciencia y Cultura, año/vol. 12, núm. 057, enero-mar- 
zo, México, Benemérita Universidad Autónoma de Puebla, 2005, 29-33.

Palerm, Ángel, Antropología y marxismo, México, CIESAS, 1998.

RAPPAPORT, Roy A., Cerdos para los antepasados. El ritual en la ecología de un pueblo en Nueva Guinea, Madrid, Siglo Veintiuno Editores, 1987.

STEWARD, J. H., Theory of Culture Change: The Methodology of Multilinear Evolution, Urbana, 1955.

STOR̊̊, Nils, "La ecología cultural y la interacción entre el hombre y su entorno", en Nissinako, A. (ed.), Cultural Ecology. One Theory? University of Turku. Turku, 1994, 11-23. Traducción de José Luis García Valdivia y L. García Sanjuán, noviembre 2003, 11, disponible en: http:/ / centro.us.es/atlas/documentos/articulos/Stora_Cultural Ecology.pdf, [consulta: abril 2008].

SzTOMPKA, Piotr, Sociología del cambio social, Madrid, Alianza Editorial, 1995.

TolEDO, Víctor M., “Repensar la conservación: ¿Áreas naturales protegidas o estrategia biorregional?", Gaceta Ecológica, octubre-diciembre, núm. 077, México, Instituto Nacional de Ecología, 2005, 47-83.

TOMÉ MARTín, Pedro, "Ecología cultural y antropología y económica", Relaciones. núm. 102, vol. XXVI, primavera, Zamora, El Colegio de Michoacán, 2005, 20-59.

Venegas PÉREZ, Ysmael, "Saberes campesinos sobre el maíz en Sevina, Michoacán", Tesis de Licenciatura para obtener el grado de Ingeniero en Agroecología, Chapingo, México, Universidad Autónoma Chapingo, 1996.

Weber, Max, Economía y sociedad, México, Fondo de Cultura Económica, 1944.

WitTFOGEL, Karl, Despotismo oriental, Madrid, Guadarrama, 1956.

Wolf, Eric, Pueblos y culturas de Mesoamérica, México, Ediciones Era, 1967.

Wolf, Eric, Europa y la gente sin historia, México, Fondo de Cultura Económica, 1987.

FeCha de ReCEPCIÓN DEL ARTí́culo: 3 de julio de 2009

FECHA DE ACEPTACIÓN Y RECEPCIÓN DE LA VERSIÓN FINAL: 15 de abril de 2010 